\title{
Designing for affect through affective matter
}

\author{
Akari Kidd and Jan Smitheram
}

\begin{abstract}
Introduction
This paper considers how affect moves us, and specifically, how we can design affective environments rather than use affect as a tool for interpretation, analysis or description of a design project. Knowing how affect moves us leads to a better understanding of how space is experienced. In recent years it has become a key theme of contemporary critical thought. Following the philosophies of Baruch Spinoza and Gilles Deleuze, scholars of the "affective turn" define affect as an intensity (Massumi 2002: 27, Gregg \& Seigworth 2010: 2). This main thread of research on affect draws a distinction between affect and emotion where emotion is something that can be enunciated for instance, statements like "I feel happy" - while affect is understood as autonomous because it occurs before we are able to name. In short, affect precedes emotion and therefore maintains a degree of autonomy from the subject. This framing of affect as autonomous provides a variety of ways of conceptualising the pre-conscious, pre-intentional, pre-verbal processes that occur between bodies. In architecture, affect, for the most part, continues this lineage of defining affect as autonomous, but critically also as an instrument of analysis. For instance Hélène Frichot's consideration of Olafur Eliasson's interior installations underscore the highly seductive and affective nature of his work where "affects are the transformative shifts in register that allow the subject to recognise his or her subjectivity in transformation" (2008: 34). While this paper acknowledges the utility of the notion of affect's autonomy - for instance, it allows for the analysis of pre-conscious experiences of the body (human and non-human) - it questions an overemphasis on this autonomy, particularly where "affective atmospheres" are presumed to be immaterial and unlocalisable (Anderson 2009: 77). Instead of using affect to analyse design or our environment, this paper builds on works like Philippe Rahm's Honorarium, which designs for affect by looking for what moves us in materialised and localisable conditions. Crucially, this paper argues for affect as a force implicit in materials. A growing concern with materiality in architecture is equally an opportunity to engage with affect. As Diana Coole and Samantha Frost explain, recent attempts to rethink materiality entail seeing matter as "always something more than 'mere' matter", instead seeing in it "an excess, force, vitality, relationality, or difference" that demands it be understood as "active, self-creative, productive, unpredictable" (2010: 9).
\end{abstract}

Two key concepts warrant clarification at this point. Firstly, the term "affect" - variously named affectus, affectio, l'affect, affect - holds a rich place in the history of philosophy. From Spinoza to Nietzsche to Deleuze, it has been taken to imply both the active senses of drive, will and desire (Spinoza 1982, Nietzsche 1968, Deleuze \& Guattari 1987) and the more passive characteristics of passion and feeling (Cox 1999: 127). However, Deleuze \& Guattari cautions against seeing affect as "a personal feeling [or...] characteristic"; instead it ought to be recognised as "the effectuation of a power of the pack that throws the self into upheaval and makes it reel” (1987: 240). In Deleuze's reading of Spinoza, affects constitute bodies according to capacities and processes of becoming. Secondly, the term "materiality" is taken to include both solid matter (for example walls and surfaces) and atmospheric or ephemeral matter (i.e., the felt and the ambient). More recently, new materiality has aimed to redirect "our attention from the materiality of objects to the properties of materials" (Ingold 2007: 12). Critical in this perspective are the expressive properties of materials - matter's relational, interactive and affective capacities (Barad 2003: 822, Latham \& McCormack 2004: 706).

Of course there are other understandings of affect. For instance, in phenomenological approaches, affect is grounded in perception, and with it, subjective, sensory experience (Russell 2006: 67). As such, affect shapes what consciousness sees, but also what bodies can do. For example, Sara Ahmed 
$(2004,2010)$ considers "happy objects" and their capacity to draw our bodies towards them. She describes, for example, how we orientate towards this or that object, how we move towards an object because we are aiming towards a feeling of happiness that we presume will follow. Ethical arguments presuppose an understanding of affect too, affects that are context-specific, influenced by cultural and social formations, and thereby are moulded responses (see Hemmings 2005; Probyn 2005). When I walk into a room, for example, my gender always exerts a pressure that will mould people's response to me. However, as Massumi notes, both these understandings may conflate emotion and affect, imparting to the latter a "content that is shaped through specific cultural, social, and political contexts" (cited in Rice 2008: 201). Following Rice (and Massumi), we assume that affect "does not have a narrative, and neither is it crafted through cultural contexts" (2008: 201).

While in architecture affect is largely associated with place and context, in this paper we describe how we have sought to utilise affect in students' design studios. In this setting, we are interested in design processes, rather than final outcomes. Particularly, we examine the design intuitions that drive the process of producing architectural spaces, rather than observe causes and responses to specific places. As such, analysis of student work usefully provides insight into how affect can be designed for. By reference to the design studio and to the theoretical discourse informing the course, this paper seeks to highlight the relationship between affect and what we have identified as new materiality above. To this end the paper is divided into two sections. Firstly, it briefly maps out affect and new materialism in the humanities and the social sciences. Secondly, moving beyond these theoretical discourses, notions of affect and materialism are considered in a pedagogical context. This paper explores design that activates and captures the spatial capacity for affect. Specifically this is done by looking at students' projects that extract materiality (through drawing/projecting), through diagramming and through atmospheric qualities.

\section{From matter-as-entity to matter-in-activity}

In this section we explore in greater detail the turn towards affect and new materialism. This exploration of the affect of matter (material affect) and effect of affect (affective materiality) is made possible by a raft of discourses centred on "materiality in-process", including contemporary feminist and cultural theory (see for example, De Landa 2004; Barad 2001, 2003; Coole \& Frost 2010). Recent thinking on new materialism is particularly useful as it undoes the common-sense conceptions of matter as passive substance, favouring instead a conception of matter as actively engendering and always in-process (see for example, Barad 2001, 2003). While there are a number of reasons for the renewal of materialism, this paper limits its scope by focusing on the work of Manuel De Landa and Karen Barad. Specifically, it looks first at matter as being characterised by "intra-activity" (Barad 2003: 817), and second, as involving what De Landa terms "intensive processes” (2002: 67). For Barad, intra-activity doesn't mean exploring "interactions" between components, as this would imply that there are independent entities from the outset. Rather the body and the building, for example, are in lively and varied intra-actions prior to any engagement with them. The innovation here involves shifting from thinking of matter as passive or separate, to active from the outset. De Landa views matter not as an object to be quantified, but rather, as something that has a capacity to act, to engage and to be transformed; matter, in this sense, is immanent and intensive.

How can matter be understood to be affectively intra-active? Karen Barad, in an interview, states that " $[\mathrm{m}]$ ateriality itself is always already a desiring dynamism ... energized and energizing, enlivened and enlivening” (Barad interviewed by Dolphijn and van der Tuin, 2012: 59). Critically for Barad matter is not mute, or held at a distance, rather it is dynamic and alive. It yearns as well as struggles as it is acted upon and acts on 'other' matter through the "stabilizing and destabilizing process of iterative intra-activity” (Barad 2003: 822; emphasis in the original). This means that 
matter has an agency. For example, living in a concrete block house involves experiencing a coolness radiating from the concrete mass and this decisively impacts on how we engage with or know the space. Concrete blocks, no less than our own bodies, engage with the world exercising force and in turn being affected by adjacent bodies of force. Intra-activity suggests that matter is necessarily composed of 'other' matter through "reconfigurings/entanglements/relationalities/(re) articulations" (Barad 2003: 818). Hence matter in Barad's work is active and has a force. Her work allows us to focus on the assemblages formed between bodies and the built and the processes that allow affect to commune.

Useful in De Landa's thinking is his recognition of matter as actively dynamic and the notion that this dynamism is affective. One particular example he uses is the formation and behaviour of metal, which continuously changes "from ductile and tough to rigid and brittle" via heating and cooling processes (2004: 17). Matter such as this is not merely self-enclosed, but assumes its characteristic states through intensive processes and transformative thresholds. In another example, De Landa considers the formation of soap bubbles which assume spherical shapes in an attempt to minimise surface tension. Rather than being complete in itself, the soap bubble reconciles the diverse tensions between individual molecules bringing them into a state of contingent reconciliation. For De Landa matter harbours a complex of intensive thresholds that anticipate or preempt particular attractor states or stabilities, states that are nevertheless coursed with "active and affective" forces (2004: 19).

The work of Barad and De Landa together make up one facet of what has been termed new materialism. In architectural design, a new materialist approach, in turn, has much to offer our understanding of materials. Further, the notion of intensive, affective formations invites the possibility that space itself may be recognised as bodies of matter sustained according to variable states of rest and transition. These matter-bodies, as Deleuze \& Guattari tell us, can be anything - a body of sounds, light, a gust of wind, human bodies - all of which engage matter in different relations and durations, and different speeds or slownesses (1987: 270). This produces a dynamic field of varying affects, and, parallel to this, a space of affective materiality (Latham \& McCormack 2004: 706). While acknowledging that all works of architecture have different degrees of affect, some design projects are more affect-abundant than others. In the next section we explore the potential of variably affective spaces via a range of student design studio projects.

\section{The design studio}

The fourth year design studio at the Victoria University of Wellington, School of Architecture was conducted in the first trimester of 2013. The studio aimed to explore architecture through material processes and the possibility that materiality itself could be understood to be atmospheric. By "atmosphere" we follow Gernot Böhme who defines it as an interstitial condition binding subjects with objects (1993: 114). As such, atmospheres may be thought to confound any straightforward appeal to either subjective or objective accounts. In fact, they foster ephemeral, affective conditions. This raises the question for us as designers of how we might think about material qualities of atmospheres themselves, particularly their agencies and relational processes. While we do not collapse Böhme's notion of atmosphere with De Landa's exposition on the intensive nature of materials, we see a synergy between the two positions around the notion of movement/process. In this sense, both are useful for this discussion, even when De Landa speaks of physical materiality and Böhme talks about less solid qualities. Nevertheless, by using the word "atmosphere" we hoped to give the students a quick way to understand and access the concerns of the studio project. In turn, students were invited to develop their own understanding of what atmosphere was or might mean. To support our discussion on affect and atmosphere they were directed towards particular new 
materialist texts to better understand matter's atmospheric qualities, including readings by, but not limited to, Barad, De Landa and Frichot.

More specifically, the project had two stages, both of which aimed to by-pass more conventional design approaches. Rather than being programme-driven and plan-orientated, the students were asked to address a process we termed "extracting materialities". As such, they were asked to identify and explore a particular affective materiality associated with one of four prescribed sites: Wellington's Civic Square; an empty site adjacent to Fidel's Café on Cuba Street; a corner site on Ghuznee and Leeds Streets; and the Left Bank Arcade. The intention was that students would use different mediums (shifting from drawing to digital rendering, to modelling) to record their selected affective materiality (refer to Fig. 1 and 2). In the second stage of the project the students were asked to create territories by shifting their initial experimentations towards a more resolved proposal (refer to Fig. 5 and 6). To aid this transition they were asked to adopt a predetermined programme - an art gallery, a supermarket, or an art gallery with a residence. Further, students could break these programmes down into constituent activities or events (for example, a bakery in the supermarket). In what we take to be a design-as-research model, the studio moved cyclically through phases of extracting materiality, diagramming their qualities and then using these qualities to create atmospheric territories on which an architectural materiality might be developed.

To exemplify these processes, two design propositions are presented in detail below. Specifically, engagements with two distinct affective materialities at two different sites in Wellington are described: firstly, deteriorating or decaying matter found at the corner of Ghuznee and Leeds Streets; and secondly, wind through the Civic Square. The first of these projects is by Grant Douglas, who explored decay on the site. In a new materialist sense, decay offers a significant affective valence because of the strong reactions people have towards it. The second project by Kelly Lambert deals with the atmospheric turbulence of wind. For Lambert wind offered an intangible, yet active material to use in design. Common to both projects was a quest to design for and with affects capable of moving us.

\section{Experimental process: extracting materialities}

Students first engaged with a process that entailed extracting materialities - in other words seeking out instances of immateriality capable of being experienced and explored corporeally.

Douglas began by capturing instances of decay at the Leeds Street site via drawing, photographing, and mapping uneven textures. Decay such as scratches, traces, and dust pointed to the ongoing inter-activity of matter vested in the site. Experimenting with rubbings, scratchings, erasures and tape markings, Douglas chronicled a tracery of previous material states, which in turn provided possibilities for crafting future transformations and alterations. By overlaying drawings he was able to describe the material force of decay on the site (Fig. 1). At stake was a quest for a deeper impression of the matter of decay than was offered by the existing site traces alone, one that emphasised the ever-changing and interactive valence of materials.

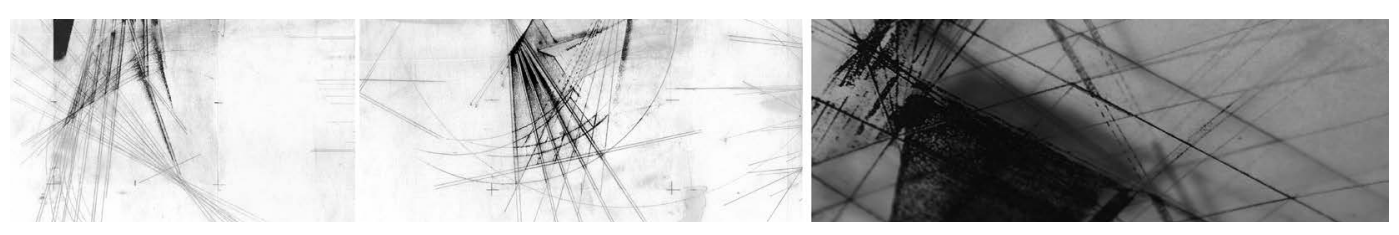

Fig. 1 Grant Douglas (2013). Experimental Process through modelling, drawing and layering. Phase 1 to 5 (from the left side): photograph of the model: two drawings tracing over the photographs of the model as the model changed; and finally, two images investigating the in-between areas of decay taken from the site and decay that he represented in his model [Model photograph and drawings, Grant Douglas] 
In Lambert's case, wind itself was seen as a material. The initial capturing process involved the construction of different forms that impede the air's movement. The models utilised different surfaces and inscribing instruments - paper and ink (Fig. 2), machine machinery and ink, sheet and film, bubbles and ink, grass and ink, flax and ink, graphite and water. In this way, wind was rendered an affecting body. As such, this project takes account of the myriad of "intra-actions" (Barad 2003: 822) between air and the body and between affecting and affected materials.
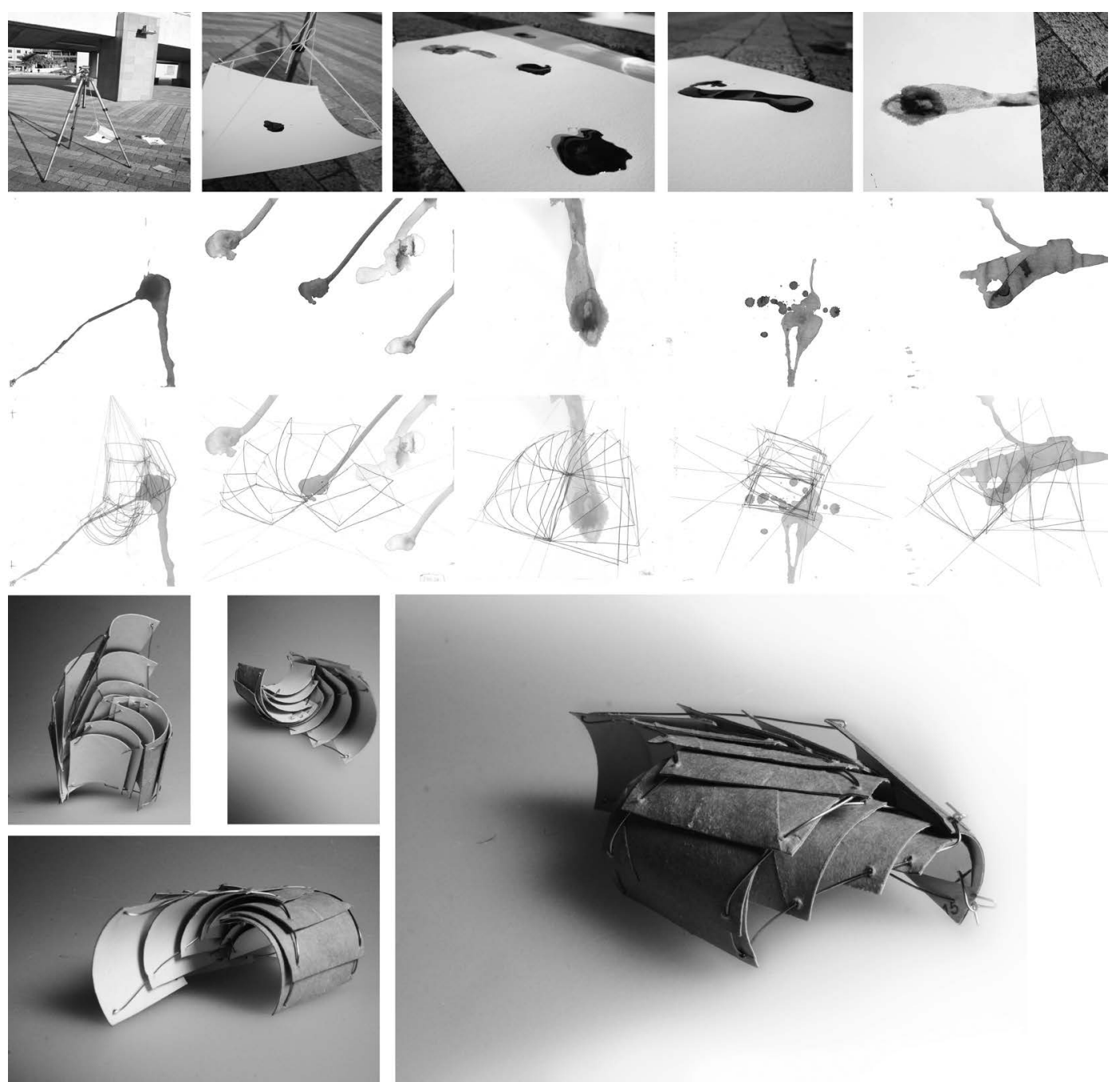

Fig. 2 Kelly Lambert (2013). Capturing Wind Movement (The images show how wind movement is caught by an instrument constructed by the student out of a tripod, strings, ink and paper. The wind movement is documented on the paper by dropping ink on it and allowing the ink to disperse according to the wind force) [Model photograph and drawings, Kelly Lambert]"

In different ways, these two projects both capture their object of examination - decay in one case, wind in another - and in turn re-materialise it via modelling, drawing, and layering. For both students, after this initial experimental process, an intermediary phase of materialising atmospheres through diagramming was pursued. 


\section{Intermediary process: materialising through diagramming}

One way of understanding how these experiments might intersect with issues of building design is through diagramming. As Peter Eisenman puts it, the diagram "acts as an intermediary in the process of generation of real space and time" (2010: 95). Eisenman tries to challenge the routine ways we approach design by inserting diagrams of DNA, for example, into design processes.

Douglas' drawn capture of materiality was then investigated for potential spatial relations. The resulting diagrams merged the affective reality of the site with the particular spatial requirements of the programmatic activities (Fig. 3). Yet these diagrams, in materialising new spatial possibilities,

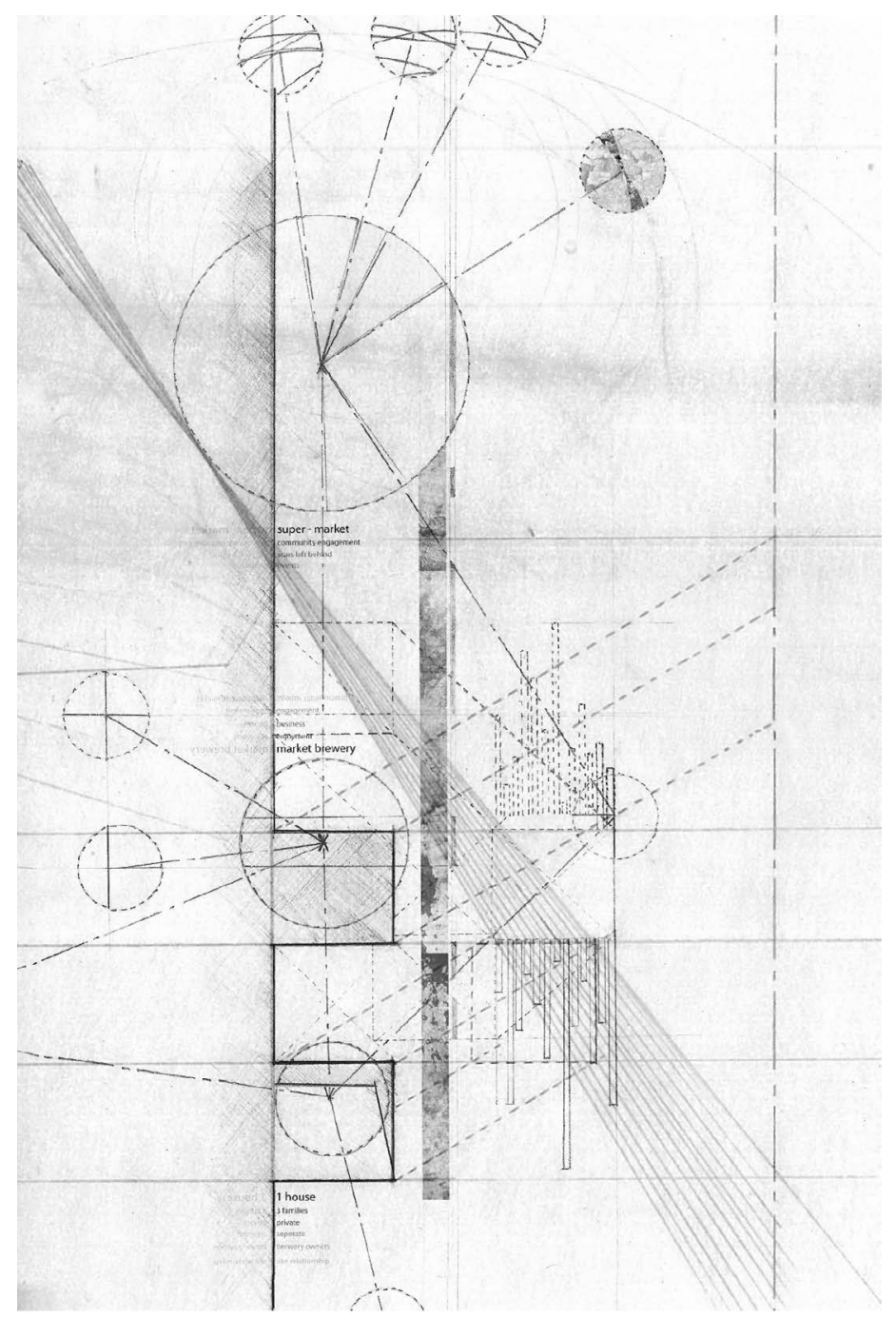

Fig. 3 Grant Douglas (2013). Diagram of Site Plan and Elevation with Texture and Programmatic Study (For this diagram Douglas overlaid the site plan and elevational drawing of the site, further montaging this with textures found on the site and the needs of the programme) [Drawing, Grant Douglas]"

themselves became active materialising agents generating expressive potential. For instance, found in this diagrammatic flatness are three-dimensional spatial fields, rich in shifting site data, programme, spatial movement and materiality. 
Similarly, in Lambert's project, diagrams are read as maps of moving materials consistent with what Latham and McCormack take to be a "cartography [of...] the eventful creativity of materiality” (2004: 708). Having built the site at a smaller scale, Lambert then conducted a wind test based on data from the site. She used graphite to observe how wind can exert pressure on material. After videoing this she took stills from the video which recorded how far the graphite dispersed over the
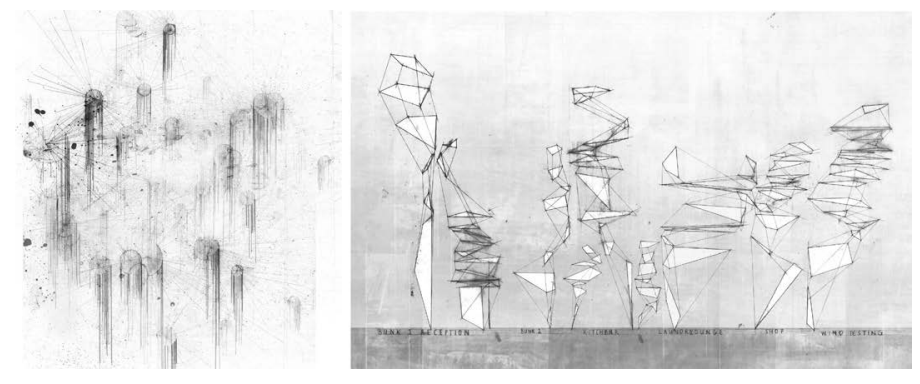

Fig: 4 Kelly Lambert (2013). Diagrams of Wind Dispersion and Form Generation (The left diagram shows the dispersion of wind on the site which is overlaid with a drawing generated through the capturing of materiality process. This generated potential forms, as illustrated in the right image) [Drawings, Kelly Lambert]"

modelled site. This dispersive action became the grounds for her diagramming (Fig. 4) and wind itself as an affective field set up the possibility of imagining different programmatic activities and, in the pushing of lines of force, an alternative basis for establishing built form.

\section{Design process: creating materialities}

With these diagrammatic exercises the process of re-materialisation, that is, creating materialities through atmosphere, was potentiated. In Douglas' case, the creating of materialities from decaying matter was projected back on to the existing building as deep incursions into a building interior.

For example, one incursion became the backpackers' lounge where an imagined solid form was carved out according to the weathering trace of the exterior wall. The resulting voided space was further extruded and projected to create a deeper impression of the decay's trace projected into the interior. Building on an ongoing interest in timber, Douglas used this material to trace imagined weathering as it would occur after the building was built. As such, timber was imagined to act as both structure and a recording device. As seen in the image below (Fig. 5, right) the stud framing is situated at the entrance as a structural element but it also acts as a sacrificial material decaying

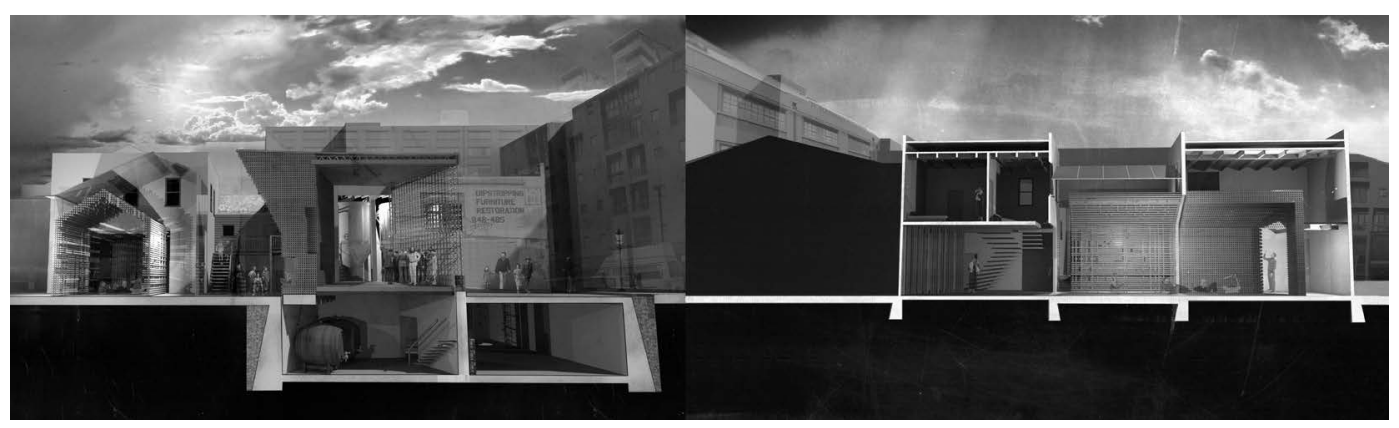

Fig. 5 Grant Douglas (2013). Backpacker's Lounge (Rendered sectional perspectives of Backpacker's Lounge interior space) [Sections, Grant Douglas]" 
over time. The space formed by this material was a lounge, so not only was it intended that the structure would decay, but it provided a space to collect items that the backpackers might leave behind. In this way, not only is the building's decay celebrated, so too is the devolving relationship of people to this place.

For Lambert the active materiality of wind finds re-materialisation through pathways for movement. Pointedly, Lambert wanted the whole site to be constantly moving and so sought a fluid intervention into the site rather than a fixed building - specifically a speculative programme described as a windmarket. In proposing this wind-market the aim was to draw our attention to the presence of wind by creating structures particularly responsive to it. In this case a crane acted as an indicator of force, resistive, yet shifting in accordance with the contingently active matter of wind. Contrastive with the rigid steel of the crane, Lambert introduces a second, tensile form to house programmatic demands. Much as the crane would respond to the wind direction, the seemingly weak materiality of the fabric would absorb and react to the impact of wind, transforming the spaces it pocketed. Lambert intended that people would, in their own way, react to the noise and the movement on the site by moving towards her architecture or away from it. The openness of the spaces allow sudden gusts of wind and
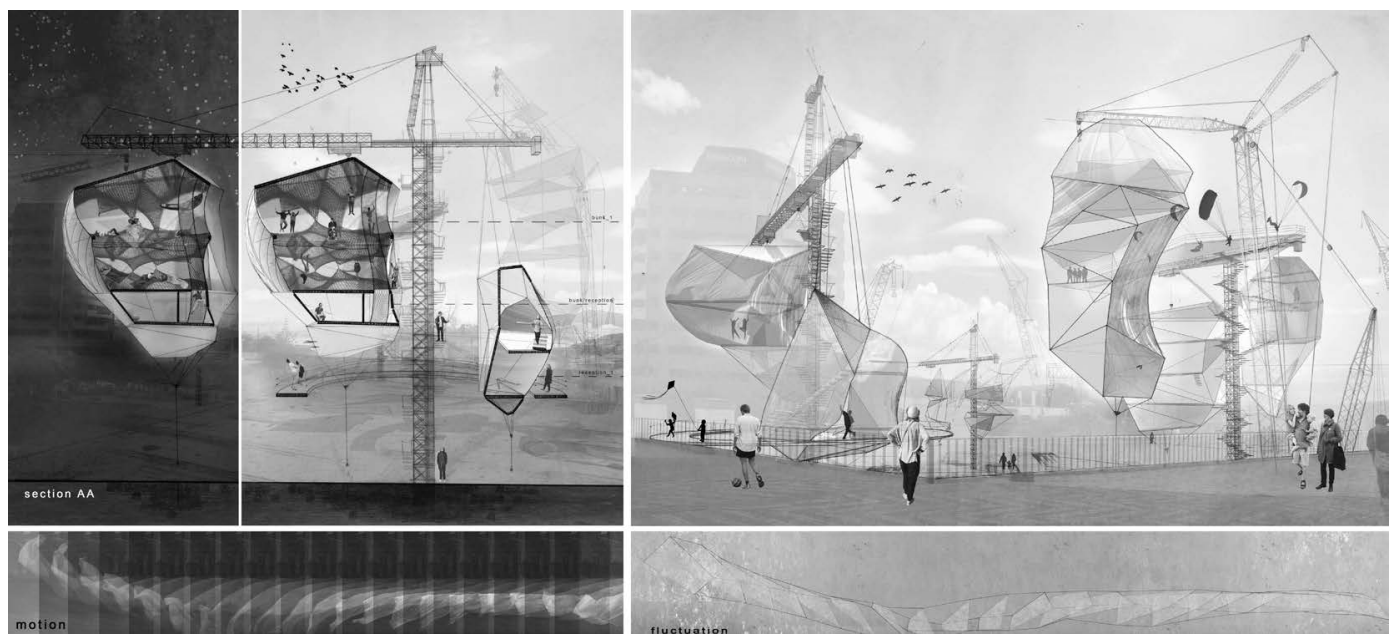

Fig. 6 Kelly Lambert (2013). Wind Market (Illustrations of speculative wind market shows how the shape changes from night to day and also when the wind blows) [Drawings, Kelly Lambert]"

rain, that is, atmospheric states, to penetrate the space, impacting on the occupants' experience (Fig. 6). These spaces are continually challenged and transformed through the action of the wind. Affect is designed for here through this intensification of the awareness between uncontrolled forces (wind) and controlled materiality. Rather than imposing form on passive-matter, the active materiality of wind collaborates in the production of the final form and its attendent atmosphere.

These projects, built on the extraction of decaying matter and air movement, illustrate approaches to materialising immateriality. In Douglas' project, markings, scratchings, and abandoned objects release and absorb intensities that impact upon and penetrate each other, resulting in spaces capable of producing and accruing roughness and clutter and, in turn, varying states of decomposition and re-materialisation. Similarly, Lambert's project proposes a re-materialisation of the atmospheric variables of the wind to create a space highly attuned to wind. 


\section{Conclusion}

In this paper, we have sought to give an affirmative use to affect in the design of environments. Rather than seeing affect as an after-effect of given spaces, we have argued for affect as a found (and an always reconstituting) force, one that stands out as a little-utilised, yet always pervasive, generative agent. In summary, three key observations relating to methodological, pedagogical and theoretical factors are warranted:

Firstly, this paper has argued for the value of engaging with theoretical discourses on affective matter and new materialism. Yet in engaging with this material, it was necessary to devise a methodological approach that allowed students to enact its insights. Utilising a stepped design process - extracting materiality, diagramming, and recreating materiality through atmosphere - designing with and for affect was achieved. Methodically drawing on what De Landa sees as an implicit, energistic movement in materials makes possible a rich, if radically different, response to locale, place and programmes (2004: 19). It is through attention to these affective materialities that we can design for affect. Potentiated in this design methodology is an advanced way of attending and attuning to what McCormack refers to as the "affectivity of atmospheric spaces" (2008: 427). Rather than commencing with a search for concepts or ideas with which to generate a project, this approach draws on the atmospheric and affective capacity of the materially given world to structure a design process.

Secondly, as a pedagogical practice, attendance on affect - something that routinely goes unnoticed because it is in the background - became for the studio group a way to both renovate existing design methodologies and to find creative resources always already available to them. Because of the institutional limits of a university design project, the results of course remain speculative yet further materialisation at built scales, rather than invalidating the findings here, would equally favour designing for affect but with more immediate effects.

Thirdly, while the study of affect is broad, the recent "affective turn" looks to go beyond the privileging of affect's autonomy, fostering instead attendance on affect's materiality and generative valance. We hope this paper further contributes to this call, arguing that a concept of affect should crucially be assessed on its ability to establish how affects are indeed localisable, material and effecting. This argument has been developed by presenting the means through which affect and matter may be connected within theoretical discourse and within a design studio. This paper has explored student works which focus primarily on the transformative particularities of affective materialities - both the material matter of decay and the atmospheric matter of wind. Following Ahmed's emphasis on the "material effects" of affect (2004c: 92), and Latham and McCormack's identification of "affective materialities" (2004: 706), we have aimed to give matter its due. Affect is clearly not an easy concept to comprehend in relation to matter, but through new materialism we can apprehend how affect may be designed for and how affect may move us. 


\section{References}

Ahmed, S. (2004). The cultural politics of emotion. Edinburgh, Scotland: Edinburgh University Press.

Ahmed, S. (2010). Happy Objects. In M. Greff and G. Seigworth (Eds.), The affect theory reader (pp. 29-51). Durham [N.C.] : Duke University Press

Anderson, B. (2009). Affective atmospheres. Emotion, Space, and Society, 2, 77-81.

Barad, K. (2001). Re(con)figuring space, time and matter. In Marianne DeKoven (Ed.), Feminist locations: Global and local, theory and practice (pp. 75-109). New Brunswick, NJ: Rutgers University Press.

Barad, K. (2003). Posthumanist performativity: Toward an understanding of how matter comes to matter. Signs: Journal of Women in Culture and Society, 28(3), 801-831.

Böhme, G. (1993). Atmosphere as the fundamental concept of a new aesthetics. Thesis Eleven, 36(1), 113-126.

Coole, D. and Frost, S. (2010). Introducing the new materialism. In D. Coole and S. Frost (Eds.), New materialisms: Ontology, agency and politics (pp. 1-43). Durham, NC and London, England: Duke University Press.

Cox, C. (1999). Nietzsche: Naturalism and interpretation. Berkeley, CA: University of California Press.

DeLanda, M. (2002). Intensive science and virtual philosophy. London, England: Bloomsbury Academic.

DeLanda, M. (2004). Material complexity. In N. Leach, D. Turnbull, and C. Williams (Eds), Digital tectonics (pp. 70-77). London, England: Wiley-Academy.

Deleuze, G. and Guattari, F. (1987). A thousand plateaus: Capitalism and schizophrenia (B. Massumi, Trans.). Minneapolis, MN: University of Minnesota Press.

Dolphijn, R. and van der Tuin, I. (2012). New materialism: Interviews \& cartographies. London, England: Open Humanities Press.

Eisenman, P. (2010). Diagram: An original scene of writing. In M. Garcia (Ed.), The diagrams of architecture (pp. 92103). London, England: John Wiley and Sons.

Frichot, H. (2008). Olafur Eliasson and the circulation of affects and percepts in conversation. Architectural Design, 78 (3), 30-35.

Gregg, M. \& Seigworth, G. (Eds.). (2010). The affect theory reader. Durham, NC and London, England: Duke University Press.

Hemmings, C. (2005). Invoking affect: Cultural theory and the ontological turn. Cultural Studies, 9(5), 548-567.

Ingold, T. (2007). Materials against materiality. Archaeological Dialogues, 14 (1), 1-16.

Latham, A. and McCormack, D. (2004). Moving cities: Rethinking the materialities of human geographies. Progress in Human Geography, 28 (6), 701-724.

Massumi, B. (2002). Parables of the virtual: Movement, affect, sensation. Durham, NC and London, England: Duke University Press.

McCormack, D. P. (2008). Engineering affective atmospheres on the moving geographies of the 1897 Andrée expedition. Cultural Geographies, 15, 413-430.

Nietzsche, F. W. (1968). The will to power: A new translation (Trans. W. Kaufmann and R. J. Hollingdale). New York, NY: Vintage Books.

Probyn, E. (2005). Blush: Faces of shame. Minneapolis, MA: University of Minnesota Press.

Rice, J. E. (2008). The new "new": Making a case for critical affect studies. Quarterly Journal of Speech 94 (2), 200212.

Russell, P. L. (2006). The phenomenology of affect. Smith College Studies in Social Work 76 (1/2), 67-70.

Sponiza, B. (1996). Ethics. London, England: Penguin.

Spinoza, B. (1982 [1677]). The ethics and selected letters (S. Shirley, Trans.). Indianapolis, IN: Hackett Publishing Company. 